\title{
Superior orbital fissure syndrome
}

\section{Some clinical and radiological observations}

\author{
J. F. HALLPIKE ${ }^{1}$
}

\author{
From the Department of Neurology, St. George's Hospital, London
}

SUMMARY A patient is described with features of a superior orbital fissure (Tolosa Hunt) syndrome and a coexistent intraorbital lesion. There was radiological evidence both of narrowing of the carotid artery and of an intraorbital obstruction of venous return from the orbit. The diagnostic value of orbital venography and carotid angiography in the investigation of granulomata in the region of the orbit is stressed. The condition described here is responsive to corticosteroids and it is also inferred that there may be a clinicopathological spectrum encompassing both the Tolosa Hunt syndrome and pseudotumour of the orbit.

A syndrome of progressive painful ophthalmoplegia due to involvement by a non-specific inflammatory process of structures traversing the superior orbital fissure is being more widely recognized (Hunt, Meagher, Lefever, and Zeman, 1961; Lakke, 1962; Smith and Taxdal, 1966; Cheah and Ransome, 1970). Knowledge of the underlying pathological process is scanty and stems largely from morbid anatomical findings in a single case (Tolosa, 1954). The purpose of the present paper is to emphasize the diverse nature of this syndrome, the place of contrast radiography including orbital venography in diagnosis, and the effectiveness of corticosteroids in treatment. The problem of differential diagnosis is discussed and on the basis of this report it is suggested tentatively that the Tolosa Hunt syndrome, so-called, has features in common with orbital pseudotumour; these two conditions might usefully be regarded as local variants of a common pathological process.

\section{CASE REPORT}

R.M., aged 43 years, an agricultural instructor, was first admitted to Atkinson Morley's Hospital ( $T$ 38162) in August 1970. He was complaining of left frontal headaches and pain behind the left eye increasing in severity for three months and waking him at night. Two weeks before admission he 1 Present address: Institute of Neurology, Queen Square, London.
WC1N 3BG. developed diplopia and the vision in his left eye began to deteriorate. Examination then showed 0 visual acuities of $6 / 5$ and $J 1$ on the right and $6 / 12$ and $\mathrm{J} 4$ on the left, corrected. The left eye was proptosedo some $2-3 \mathrm{~mm}$. The left optic disc was swollen with $\stackrel{\mathrm{Q}}{\mathrm{Q}}$ full veins but without other fundal abnormalities. Visual fields appeared full. Horizontal and vertical diplopia were present and found to be due to weak 응 ness of elevation and adduction of the left eye. The pupils were normal and there was no ptosis. Corneafo responses were present and no sensory loss was found on the face. Clinical examination was otherwise normal; there were no bruits and the blood pressure was $145 / 80 \mathrm{mmHg}$.

Routine urinalysis and the peripheral blood picture were normal. The ESR was $9 \mathrm{~mm} / 1 \mathrm{hr}$ (Wintrobe). Plasma electrolytes, blood sugar, blood urea, and protein-bound iodine were all in the normal range. The cerebrospinal fluid (CSF) was under normal pressure and contained $15 \mathrm{mg}$ protein/ $100 \mathrm{ml}$. with no cells. The WR was negative in blood and CSF. Plain radiographs of the skull, optic foramina, and nasal sinuses were normal. Radiographs of the chest showed hilar calcification. An electroencephalogram showed a left temporal abnormality but a technetium brain scan was negative. The left carotid angiogram showed slight displacement of mid-line vessels to the right. Lumbar pneumoencephalography also disclosed a $3 \mathrm{~mm}$ shift of the septum pellucidum and of the left temporal horn towards the right. Although slight, these radiological abnormalities were consistent and indicative of a space-occupying lesion in the left temporal fossa. 

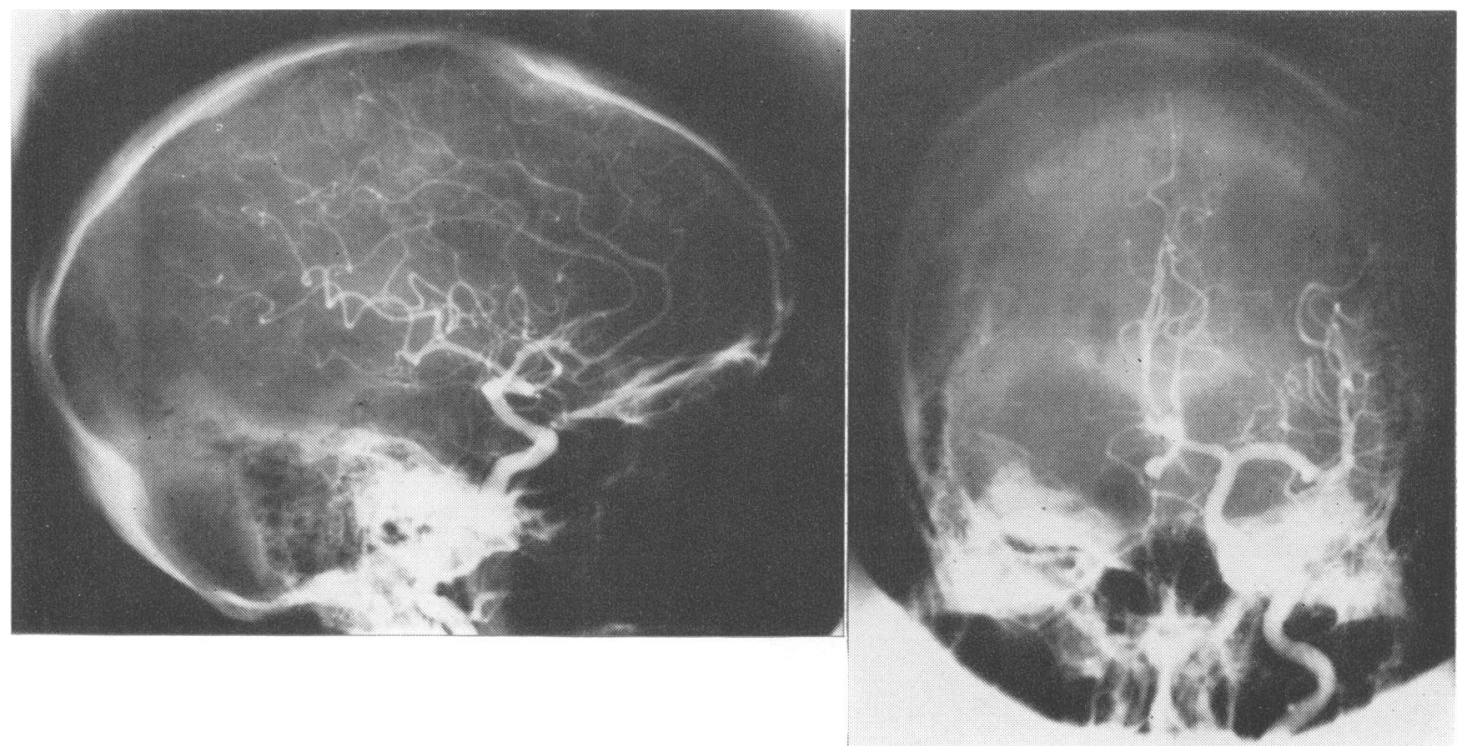

(a)

(b)
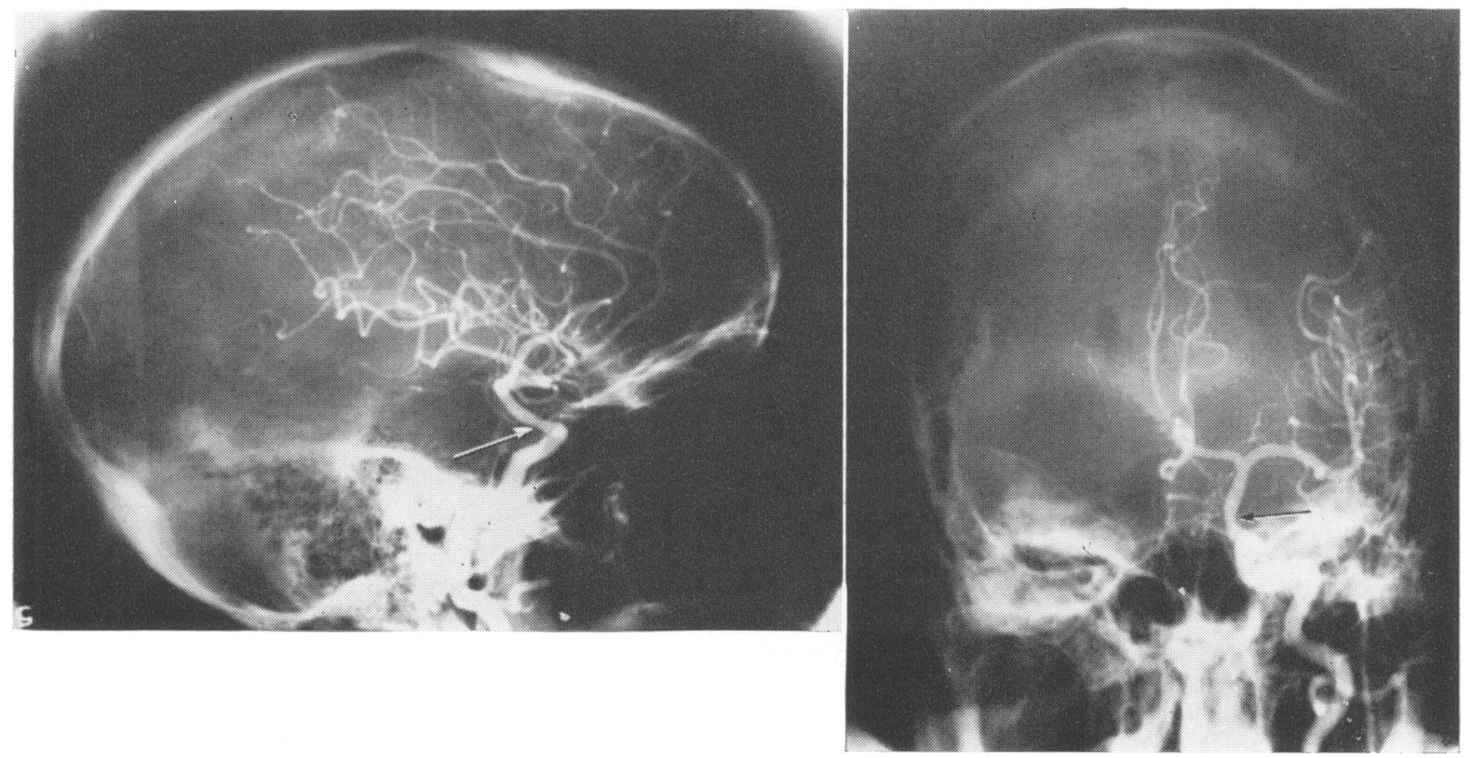

(c)

(d)

FIG. 1. Left carotid angiogram, lateral (a) and AP (b) views taken in August 1970 during first admission; (c) and (d), identical views from the February 1971 admission showing arterial narrowing (arrows). 
Initial treatment with dexamethasone ( $2 \mathrm{mg}$ q.i.d.) and tetracycline ( $250 \mathrm{mg}$ q.i.d.) promptly relieved his headache and eye pain. Six weeks after starting this treatment the left visual acuity had improved to N5 and the unilateral papilloedema was resolving. The dose of corticosteroids was gradually reduced and finally withdrawn after six weeks. He remained symptomless with N5 visual acuity and normal appearance of the optic discs.

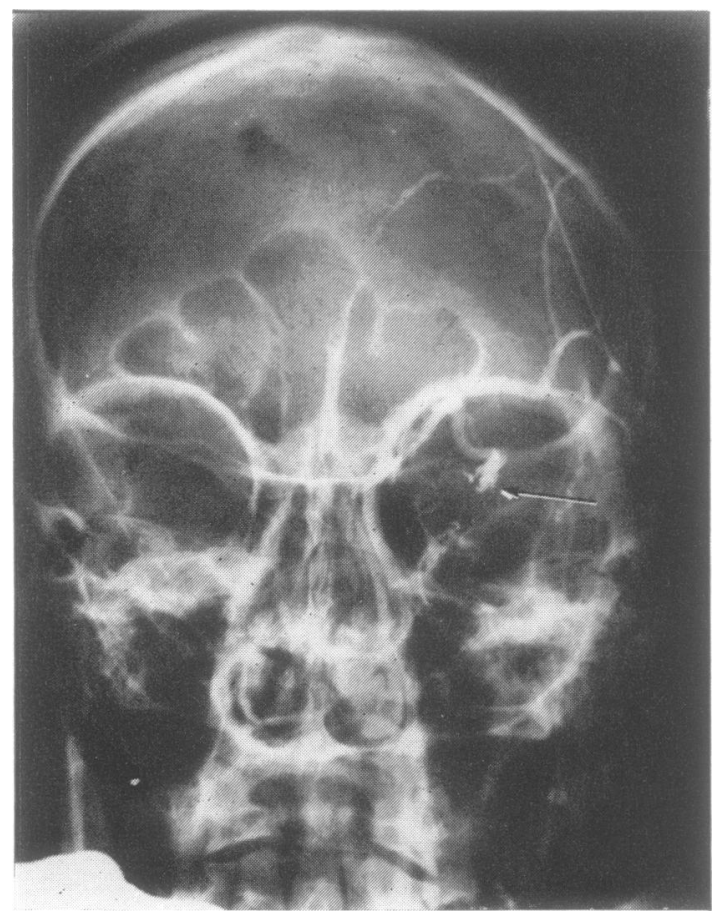

FIG. 2. Orbital venogram (February 1971) showing obstruction (arrow) of the third part of the superior ophthalmic vein.

In February 1971, some six months after the initial episode, he presented with a recurrence of left orbital pain and rapidly deteriorating vision in the left eye. The visual acuities measured then were VAR N5 and VAL N48 corrected. The left eye again showed proptosis of some $2-3 \mathrm{~mm}$. There was marked swelling of the left optic disc and a small central scotoma judged by confrontation with a $3 \mathrm{~mm}$ red target. Ocular movements were normal without diplopia and both corneal responses were brisk. Treatment with dexamethasone $(4 \mathrm{mg}$ t.i.d.) was commenced at once. Within 48 hours the pain had largely disappeared. The scotoma could no longer be detected and the visual acuity in the left eye had improved to N12. Urine and haematological investigations carried out on the previous admission were repeated and again found normal. The ESR was $4 \mathrm{~mm} / 1 \mathrm{hr}$. The left carotid angiogram was repeated: the proximal part of the left anterior cerebral artery was thought to be slightly elevated and bowed towards the right. In addition, compared with the arteriogram of the previous August, there was pronounced narrowing of a segment of the supraclinoid portion of the internal carotid artery (arrow, Fig. 1) and moderate constriction of this vessel above and for a short distance below the origin of the ophthalmic artery. Both arteriograms were carried out under general anaesthesia and the film series appeared strictly comparable. An orbital venogram was performed by left frontal vein puncture and with facial vein compression. An occlusion of the superior ophthalmic vein was found in its third part (Fig. 2) with little drainage into the cavernous sinus.

An exploratory left frontal craniotomy was carried out by Mr. Alan Richardson on 12 March 1971. The subfrontal, optic chiasm, left optic nerved and sellar regions all appeared normal. Recovery from the operation was uneventful and he was 2 shortly discharged, taking dexamethasone $2 \mathrm{mg} \cdot \vec{c}$ t.i.d., symptom free and with VAL N8. The steroid dosage was reduced gradually during follow-up and discontinued after three months. The disc appear $\overrightarrow{0} \cdot \overrightarrow{0}$ ances returned to normal during this period and he has remained well, free of headache and with VAL $\mathrm{N} 4.5$ for the past nine months.

\section{DISCUSSION}

The concomitant occurrence of headache, ocular pain, unilateral ophthalmoplegia, and sensory loss in the first trigeminal division is frequently found to be due to an intracavernous carotid aneurysm (Symonds, 1927; Jefferson, 1937). The differential diagnosis includes cavernous sinus thrombosis, ophthalmoplegic migraine (see Brugghen, 1955), and diabetes mellitus. A variant of this clinical syndrome, characterized by spontaneous remission and subacute onset, had been recognized previously by Collier (1921) and attributed to an inflammatory process of the superior orbital fissure. One of Collier's cases followed a relapsing course. Eduardo Tolosa (1954) reported a patient in whom carotid arteriography, after the onset of a painful 
external ophthalmoplegia, failed to demonstrate an aneurysm but did show narrowing of the carotid siphon. Necropsy in this patient revealed non-specific granulation tissue invading the cavernous sinus compressing the carotid artery and wrapping the emerging nerve trunks. Hunt et al. (1961) described six patients with episodic retro-orbital pain accompanied by ipsilateral ophthalmoplegia. Carotid arteriography failed to show any aneurysm and two patients in this series improved with administration of corticosteroids.

Conspicuous features of the present case, in both hospital admissions, were the unilateral orbital pain, ipsilateral swelling of the optic disc, and diminished visual acuity. Although present initially, ophthalmoplegia was both transient and partial. No trigeminal sensory loss was found. Hence, with failure to demonstrate an aneurysm, clinical suspicion on the first admission turned towards an inflammatory or granulomatous process affecting the orbit. The radiological evidence of a space-occupying abnormality in the middle fossa suggested that this inflammatory process might not be confined to the orbit. Of the 16 cases of orbital pseudotumour described by Jellinek (1969) vision was affected in eight and minor degrees of ventricular displacement were present on pneumoencephalography. Six patients in Jellinek's series received corticosteroids and all showed improvement. Similar clinical and therapeutic findings in orbital pseudotumour have been reported elsewhere (Coop, 1961 ; Mortada, 1965). Thus, a diagnosis of orbital pseudotumour responding to dexamethasone seemed probable after our patient's first admission to hospital. Cessation of steroid treatment was followed by a recurrence of previous symptoms but with more severe loss of vision accompanied by a scotoma and optic disc oedema. Repeat carotid angiography showed narrowing of the supraclinoid and to a lesser extent the intracavernous portion of the internal carotid artery (Fig. 1). Such narrowing of the carotid artery accords well with the radiological changes described by Tolosa (1954) in his original report. Orbital venography disclosed an intraorbital obstruction of the superior ophthalmic vein with failure to fill the cavernous sinus (Fig. 2). Similar findings occur in orbital pseudotumour investigated by venography (see McNulty, 1969) but cannot be considered diagnostic.

Of interest in this case is the occurrence of features both of orbital pseudotumour and the clinical picture described by Tolosa (1954) and elaborated by Hunt et al. (1961). The Tolosa Hunt syndrome appears to be a unilateral, selflimiting or relapsing affection of structures traversing the superior orbital fissure. However, optic nerve involvement has also been described in a few cases of the Tolosa Hunt syndrome, although not accounted for (Hunt et al., 1961; Øther, 1967). In one previous report (Milstein and Morretin, 1971) of the use of orbital venography in the investigation of a superior orbital fissure syndrome the radiological abnormalities closely resembled those found in the present case and venous return to the cavernous sinus was restored after corticosteroid treatment. It seems reasonable to conclude that in the present case there was an intraorbital extension of the granulomatous process which arose in the region of the cavernous sinus or superior orbital fissure and that this was sufficient to cause the disc swelling, transient proptosis, and impairment of visual acuity. The radiological findings (Figs 1 and 2) are entirely consistent with Tolosa's (1954) observations and provide clear support for the idea that a localized granulomatous process is responsible. Although this report casts no fresh light on pathogenesis, evidence of clinical overlap between the Tolosa Hunt syndrome and orbital pseudotumour emerges; these two unusual but anatomically closely related disorders also have pathological features in common and responsiveness to corticosteroids.

I am grateful to Dr. P. C. Gautier Smith and Mr. Alan Richardson for permission to report this case and to Dr. James Ambrose and Dr. Geoffrey Hart for their help in interpreting the radiological data.

\section{REFERENCES}

Brugghen, A. V. (1955). Pathogenesis of ophthalmoplegic migraine. Neurology (Minneapolis), 5, 311-318.

Cheah, J. S., and Ransome, G. A. (1970). Collier's syndrome (orbital periostitis). Medical Journal of Australia, 1, 277278.

Collier, J. (1921). Discussion on ocular palsies. Proceedings of the Royal Society of Medicine, 14, 10-11.

Coop, M. E. (1961). Pseudotumour of the orbit. A clinical and pathological study of 47 cases. British Journal of Ophthalmology, 45, 513-542. 
Hunt, W. E., Meagher, J. N., Lefever, H. E., and Zeman, W. (1961). Painful ophthalmoplegia. Neurology (Minneapolis), $11,56-62$.

Jefferson, G. (1937). Compression of the chiasma, optic nerves, and optic tracts by intracranial aneurysms. Brain, 60, 444-497.

Jellinek, E. H. (1969). The orbital pseudotumour syndrome and its differentiation from endocrine exophthalmos. Brain, 92, 35-58.

Lakke, J. P. W. F. (1962). Superior orbital fissure syndrome. Archives of Neurology, 7, 289-300.

McNulty, J. G. (1969). Phlebography of the orbital venous system and the cavernous sinus. British Journal of Radiology, 42, 113-121.

Milstein, B. A., and Morretin, L. B. (1971). Report of a case of sphenoid fissure syndrome studied by orbital venography. American Journal of Ophthalmology, 72, 600-603.
Mortada, A. (1965). Unilateral proptosis of unexplained origin. Part III. British Journal of Ophthalmology, 49, 547553.

Øther, A. (1967). Painful ophthalmoplegia. Report of a case. Acta Ophthalmologica, 45, 371-373.

Smith, J. L., and Taxdal, D. S. R. (1966). Painful ophthalmoplegia. The Tolosa-Hunt syndrome. American Journal of Ophthalmology, 61, 1466-1472.

Symonds, C. P. (1923). Contributions to the clinical study of intracranial aneurysms. 1. Guy's Hospital Reports, 73, 139-158.

Tolosa, E. (1954). Periarteritic lesions of the carotid siphon with the clinical features of a carotid infraclinoid aneurysm. Journal of Neurology, Neurosurgery, and Psychiatry, 17, 300-302. 